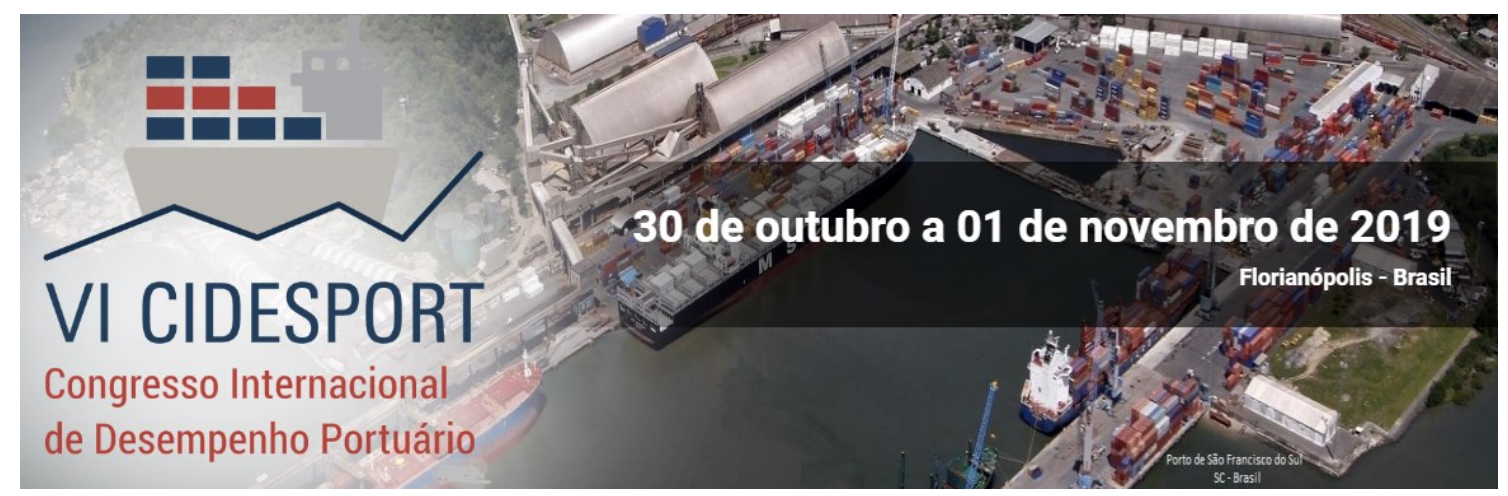

\title{
ANÁLISE DA EFICIÊNCIA DE TERMINAIS DE GRANÉIS SÓLIDOS UTILIZANDO O MÉTODO DA ANÁLISE ENVOLTÓRIA DE DADOS (DEA)
}

\author{
Jully Anne Giacomin \\ Universidade Federal de Santa Catarina \\ Vanina Macowski Durski Silva \\ Universidade Federal de Santa Catarina
}

\begin{abstract}
Resumo: O crescimento do mercado mundial implica no aumento do fluxo de mercadorias e, consequentemente, há um aumento na demanda por serviços de transporte marítimo. As empresas tendem a realizar investimentos em infraestrutura e tecnologia no transporte no intuito de se manterem competitivas. À vista disso, tornase evidente a necessidade de estudos para aumentar a eficiência do setor portuário. Assim, o presente trabalho apresenta o estudo da eficiência relativa de terminais de granéis sólidos brasileiros utilizando o método de análise envoltória de dados (Data Envelopment Analysis - DEA). Para isso foram selecionados 27 terminais, sendo que oito importam carvão, nove exportam minério de ferro e dez exportam soja, e adotados quatro inputs e dois outputs. Os resultados mostraram uma tendência de superioridade de eficiência em terminais exportadores diante dos importadores.
\end{abstract}

Palavras-chave: Eficiência. Terminais de Granéis Sólidos. Análise Envoltória de Dados. DEA.

\section{INTRODUÇÃO}

A indústria marítima trouxe mudanças significativas no transporte de grandes volumes de carga, possibilitando a integração do comércio global. $O$ avanço da tecnologia marítima implicou na redução de aproximadamente $60 \%$ no custo deste transporte comparando a década de 80 com o início do século 20. Entre 1990 e 2015, a taxa de crescimento do transporte marítimo, em volume de carga, aumentou em $151,5 \%$, tendo como forças motrizes as tendências do PIB e do comércio mundial (LUNDGREN, 1996; PROFILLIDIS e BOTZORIS, 2019).

Segundo a United Nations Conference on Trade and Development (UNCTAD, 2018), o volume de tráfego marítimo alcançou 10,7 bilhões de toneladas em 2017 . A carga seca foi responsável por 7,6 bilhões de toneladas, sendo que os principais granéis sólidos (carvão, minério de ferro e grãos) atingiram 42,3\% deste volume, seguido por cargas em contêineres $(24,3 \%)$ e outros granéis sólidos $(33,4 \%)$. De acordo com a Figura 1, percebe-se o crescente aumento de transporte de carga dos principais granéis sólidos; e assim, desperta-se um interesse por maior detalhamento no estudo sobre este tipo de carga, no qual se verifica uma média de crescimento anual de cerca de $5 \%$ no volume de toneladas comercializadas.

*A revisão gramatical, ortográfica, ABNT ou APA foi realizada pelos autores. 
Figura 1 - Comércio Marítimo Internacional (milhões de toneladas)

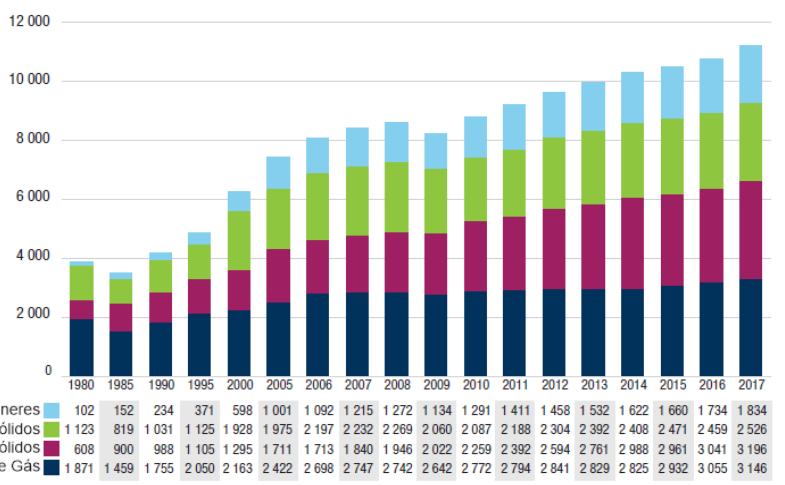

Fonte: Adaptado UNCTAD (2018)

O fluxo da movimentação de carga granel sólido varia de acordo com os diferentes produtos transportados. De acordo com a Mltsui O.S.K. Lines (MOL, 2017), o maior volume do transporte de carvão mineral navega pelo Oceano Pacífico e concentra-se na Ásia e Oceania; quanto às rotas pelo Oceano Atlântico destacam-se os países exportadores Colômbia e África do Sul e os importadores incluem Estados Unidos, Reino Unido e Alemanha. Tratando-se das rotas marítimas de minério de ferro, as mesmas têm origem em países produtores como Brasil e Austrália em direção a China, majoritariamente. Já o transporte marítimo de grãos parte dos Estados Unidos, Rússia e Argentina para Ásia e África.

No que diz respeito ao panorama das economias latino-americanas, segundo Wilmsmeier et al. (2012), a América Latina vive um paradoxo entre ser um potencial fornecedor de commodities e deficiente no desenvolvimento de setores portuários, tais como, infraestrutura dos terminais, acessos náuticos e de sistemas multimodais.

No Brasil, ao contrário do que acontece com outros tipos de carga a granel, o granel agroalimentar é movimentado majoritariamente por portos públicos. Em longo prazo, a previsão de um grande crescimento da demanda por grãos, especialmente a soja, implicará em uma lacuna entre a demanda e a atual capacidade portuária brasileira, em milhões de toneladas, como se percebe através da Figura 2.

Figura 2 - Previsão do tráfego de grão no Brasil (milhões de toneladas)

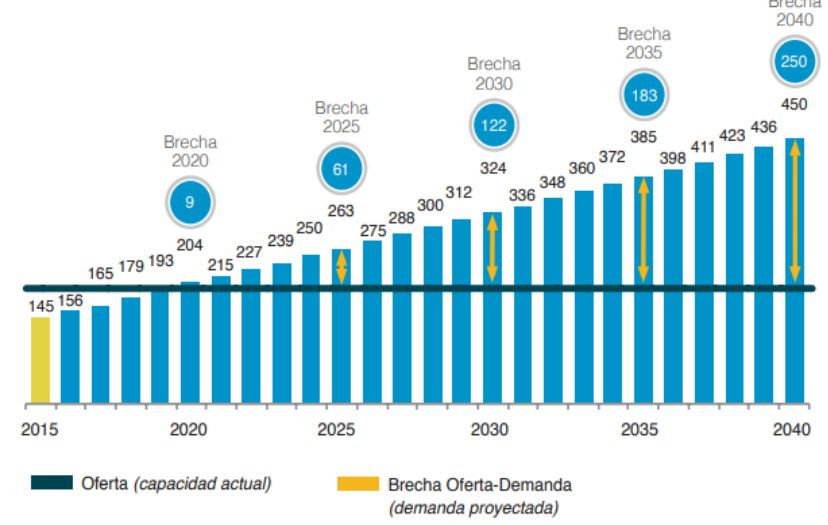

Fonte: CAF - Banco de Desenvolvimento da América Latina (2016)

Diante deste contexto, ressalta-se a importância de estudos voltados à eficiência de terminais portuários brasileiros. A fim de alcançar bons resultados e notoriedade no cenário mundial, é necessário identificar e analisar as possíveis variáveis da problemática de eficiência portuária e propor soluções adequadas. Assim, 
dada à expressividade do volume nacional/mundial movimentado de granel sólido, neste trabalho será enfatizado o estudo da eficiência dos terminais de granéis sólidos do Brasil com o auxílio do Método Análise Envoltória de Dados (DEA).

\section{REFERENCIAL TEÓRICO}

\subsection{Granel sólido}

Segundo Magalhães (2011), os granéis sólidos são mercadorias transportadas sem embalagem, lançadas diretamente nos porões dos navios por gravidade através de carregadores mecânicos ou shiploaders. O diagrama esquemático do embarque destas mercadorias está exposto na Figura 3; as operações de descarregamento ocorrem no sentido inverso do diagrama, contudo utilizando equipamentos de descarga do tipo grab, caçambas automáticas ou descarregadores contínuos.

Figura 3 - Diagrama esquemático do embarque de minérios e carvão

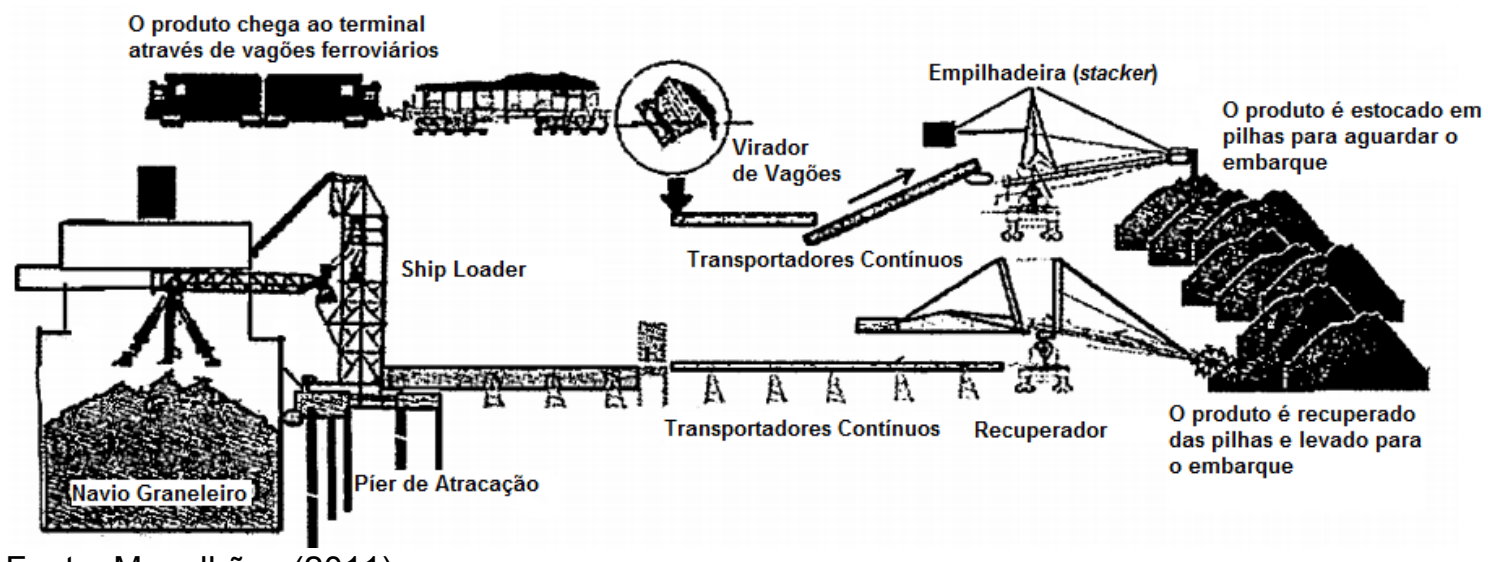

Fonte: Magalhães (2011)

Quanto ao sentido de movimentação, embarque ou desembarque, existem diferenças significativas quanto à prancha média (ton/hr) e tempo de operação, já que geralmente encontram-se operações de carregamento contínuas e de descarregamento descontínuas.

Vianen, Ottjes e Lodewijks (2013), dividem os terminais de granéis sólidos entre exportadores e importadores, considerando que os países produtores ou com maiores reservas minerais tendem a suprir a demanda de países que necessitam destes produtos base.

A América do Sul é um importante exportador de commodities. Segundo dados do The Observatory of Economic Complexity (OEC) - Observatório da Complexidade Econômica, em 2017, os países sul americanos foram responsáveis por cerca de $54,4 \%$ das exportações de soja, $23,5 \%$ das exportações de minério de ferro e $6,3 \%$ das exportações de carvão no mundo, em bilhões de dólares.

Ao realizar a análise destes dados por país, identifica-se o Brasil como um destaque mundial nas exportações de soja e minério de ferro, sendo o principal representante sul-americano, correspondendo, respectivamente, a $45 \%$ e $22 \%$ do total em bilhões de dólares exportados; conforme a Tabela 1. Quanto à exportação de carvão mineral, o país apresenta valores mais significativos nas importações. 
VI CIDESPORT/2019

Congresso Internacional

de Desempenho Portuário

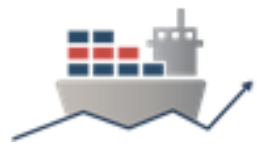

Tabela 1 - Movimentação brasileira por produto (em bilhões de dólares)

\begin{tabular}{lccc} 
Produto & $\begin{array}{c}\text { Total de } \\
\text { Exportações (em } \\
\text { bilhões) }\end{array}$ & $\begin{array}{c}\text { Total de } \\
\text { Importações (em } \\
\text { bilhões) }\end{array}$ & $\begin{array}{c}\text { \% em } \\
\text { relação ao } \\
\text { mundo }\end{array}$ \\
\hline SOJA & 26,15 & - & $45,00 \%$ \\
\hline MINÉRIO DE FERRO & 20,46 & - & $22,00 \%$ \\
\hline CARVÃO & - & 2,93 & $2,40 \%$ \\
\hline
\end{tabular}

Fonte: Baseado em OEC (2017)

Segundo dados da Agência Nacional de Transportes Aquaviários - ANTAQ (2018) o minério de ferro foi responsável por embarcar $67 \%$ do total de toneladas de granéis sólidos Brasil, enquanto a soja correspondeu a 15\%. Quanto aos produtos desembarcados no país, o carvão correspondeu a $20 \%$ dos granéis sólidos, conforme a Tabela 2.

Tabela 2 - Movimentação de granéis sólidos no Brasil (em toneladas)

\begin{tabular}{lcc}
\multicolumn{1}{c}{ Produto } & $\begin{array}{c}\% \text { do Total } \\
\text { Embarcado }\end{array}$ & $\begin{array}{c}\% \text { do Total } \\
\text { Desembarcado }\end{array}$ \\
\hline Minério de Ferro & $67 \%$ & - \\
Soja & $15 \%$ & - \\
Carvão Mineral & - & $20 \%$ \\
Outros Granéis & $18 \%$ & $80 \%$ \\
\hline
\end{tabular}

Fonte: Baseado em ANTAQ (2018)

Baseando-se nestes dados, a pesquisa dos terminais brasileiros pôde ser norteada; na qual foram selecionados os principais terminais de granéis sólidos do país a partir das informações do Anuário da ANTAQ de 2018, no tocante ao número de toneladas movimentadas no ano de 2018. As Tabelas 3, 4 e 5 correspondem respectivamente aos principais terminais movimentadores de minério de ferro, soja e carvão mineral.

Tabela 3 - Terminais de Minério de Ferro Selecionados

\begin{tabular}{lcc} 
TERMINAL & ESTADO & $\begin{array}{c}\text { CARREGAMENTO } \\
\text { ANUAL (Mton/ano) }\end{array}$ \\
\hline Ponta da Madeira & MA & 197,09 \\
Tubarão & ES & 96,73 \\
Itaguaí & RJ & 48,46 \\
Ilha Guaíba & RJ & 41,18 \\
Porto Sudeste do Brasil & RJ & 10,64 \\
Porto Do Açu & ES & 3,22 \\
Porto Gregório Curvo & MS & 2,47 \\
Granel Química Ladário & MS & 0,71 \\
Terminal Marítimo Ponta Ubu & ES & 0,08 \\
\hline Font Autora (2019)
\end{tabular}

Fonte: Autora (2019)

Tabela 4 - Terminais de Soja Selecionados

\begin{tabular}{lcc} 
TERMINAL & ESTADO & $\begin{array}{c}\text { CARREGAMENTO } \\
\text { ANUAL (Mton/ano) }\end{array}$ \\
\hline Santos & SP & 15,57 \\
Paranaguá & PR & 15,36
\end{tabular}


VI CIDESPORT/2019

Congresso Internacional

de Desempenho Portuário

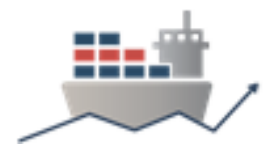

\begin{tabular}{lll} 
Itaqui & MA & 8,54 \\
Rio Grande & RS & 6,56 \\
São Francisco Do Sul & SC & 5,48 \\
Terminal De Tubarão - TPD & ES & 4,08 \\
Terminal Portuário Cotegipe & BA & 3,78 \\
Terbian - Terminal Bianchini & RS & 3,59 \\
Tiplam & SP & 3,30 \\
Terminal Graneleiro Hermasa & AM & 2,71 \\
\hline
\end{tabular}

Fonte: Autora (2019)

Tabela 5 - Terminais de Carvão Selecionados

\begin{tabular}{lcc} 
TERMINAL & ESTADO & $\begin{array}{c}\text { CARREGAMENTO } \\
\text { ANUAL (Mton/ano) }\end{array}$ \\
\hline Terminal De Praia Mole & ES & 10,40 \\
Terminal Portuário Do Pecém & CE & 5,17 \\
Ternium Br & RJ & 3,08 \\
Itaguaí (Sepetiba) & RJ & 2,44 \\
Itaqui & MA & 0,64 \\
Vila Do Conde & PA & 0,57 \\
Vitória & ES & 0,40 \\
Porto Do Açu Operações S.A. & RJ & 0,24 \\
Imbituba & SC & 0,10 \\
\hline
\end{tabular}

Fonte: Autora (2019)

A partir do panorama geral dos granéis sólidos é possível prosseguir para a verificação do conceito de eficiência, bem como analisar as variáveis que exercem influência na problemática do transporte marítimo.

\subsection{Eficiência e eficiência portuária}

De acordo com Sobral et al. (2013), eficiência é a capacidade de realizar as operações minimizando a utilização de recursos, desempenhando corretamente as atividades sem que o prejuízo pelo desempenho seja elevado. Eficiência é a relação ótima entre os resultados atingidos e os recursos consumidos.

Farrell (1957) foi um dos pioneiros a compor a fundamentação teórica para estudar e medir a eficiência. O autor divide a eficiência em técnica e alocativa. A primeira mede o desempenho de uma unidade produtiva a partir da capacidade de produção máxima de um determinado conjunto de insumos, já a segunda refere-se à capacidade de uma organização de encontrar as proporções ótimas de input e output adequadas aos atuais preços.

Através da generalização do modelo de Farrell foi possível a criação do método da Análise Envoltória de Dados abordado no presente trabalho e, baseado no mesmo, encontrar as eficiências produtivas e técnicas dos terminais analisados. A Análise Envoltória de Dados decompõe a eficiência produtiva em: eficiência de escala e eficiência técnica. Segundo Belloni (2000), "a eficiência de escala, é aquela associada a variações da produtividade decorrentes de mudanças na escala de produção, e a eficiência técnica, associada à habilidade gerencial da organização".

A eficiência de produção pode ser medida a partir da comparação dos valores observados e dos valores ótimos de input e output. Sendo assim, é necessário confrontar os valores obtidos de output, a partir dos inputs consumidos, com os valores 


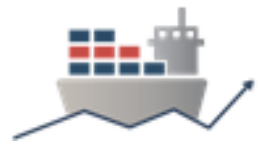

dos potenciais máximos de outputs, ou observar os valores dos mínimos inputs requeridos e comparar com os inputs que foram utilizados, mantendo os outputs constantes, ou ainda uma combinação dos dois casos (LOVELL et al., 1985).

Em se tratando da eficiência portuária, um porto pode melhorar a sua eficiência à medida que minimiza tempo de permanência de uma embarcação, ou seja, diminui os tempos de espera para atracação, de operação e de liberação do navio. A eficiência portuária também é medida segundo a performance operacional, infraestrutura e segurança das operações (FIGUEIREDO, 2001).

Para Schott e Lodewijks (2007), os fatores operacionais que podem prejudicar a produtividade de um terminal de granel sólido são o layout, as características dos equipamentos utilizados para operações de carga e descarga e capacidade de armazenamento. O trabalho de Vianen, Ottjes e Lodewijks (2013) ressalta a importância do dimensionamento de pátios de estocagem para terminais mineraleiros, pois afirmam que uma pequena capacidade de armazenagem resulta no aumento do tempo de espera de navios, e grandes dimensões de pátio dificultam a recuperação do investimento.

\subsection{DEA}

A Análise Envoltória de Dados é um método matemático fundamentado na lógica de programação linear que possibilita comparar eficiências entre diferentes unidades produtivas (neste estudo, terminais portuários), utilizando critérios de entrada e de saída. A partir deste modelo matemático, pode-se alcançar um percentual de eficiência para cada unidade produtiva e analisar quais delas servem de parâmetros e quais ainda podem ser otimizadas (CHALRÉO, 2015).

Segundo Novaes (2006), o DEA é uma abordagem não paramétrica, pois não requer, previamente, a escolha de uma função matemática. As DMUs (Decision Making Unit) são as unidades tomadoras de decisão e representam empresas, organizações ou setores a serem comparados na análise. Para Kassai (2002) a vantagem deste método está no fato dele prescindir a atribuição de pesos e através da programação linear, determinar quais DMUs serão utilizadas para construção da fronteira produtiva e servirão de parâmetro de benchmarking.

Segundo Cullinane (2010) a origem desta técnica encontra-se no trabalho de Charnes, Cooper e Rhodes (1978), que possibilitou a utilização de múltiplos inputs e outputs, permitindo a construção de fronteira de produção sem uma referência prédefinida, além de resultar no Modelo CCR. Mais tarde, em 1984, Banker, Charnes e Cooper, desenvolveram o Modelo BCC que permitiu retornos variáveis ao Método DEA. Estes dois modelos, CCR e BCC, são os mais clássicos e difundidos. O primeiro fornece valores de retorno com escala constante, ou seja, as variações dos insumos influem em variações proporcionais nos produtos e, obtém-se um indicador de eficiência produtiva avaliando a eficiência global. Já no segundo modelo, os retornos deixam de ser proporcionais e passam a ser convexos, permitindo que baixos valores de inputs resultem em altos retornos nos outputs. O BCC fornece um indicador de eficiência técnica (KASSAI, 2002).

\subsubsection{Modelo CCR}

O modelo criado por Charnes, Cooper e Rhodes em 1978 (CCR) também é conhecido como CRS (Constante Retorno de Escala, traduzido da sigla em inglês). 
Segundo Mello et. al (2005), a eficiência deste modelo pode ser calculada a partir da razão entre a soma ponderada dos outputs e a soma ponderada dos inputs:

Eficiência $=\frac{\text { Soma ponderada dos produtos }}{\text { Soma ponderada dos recursos }}$

A formulação matemática é descrita pela função objetivo (1), na qual as variáveis $u$ e $v$ correspondem aos pesos atribuídos a cada input e output, respectivamente. $\mathrm{O}$ modelo DEA permite que cada DMU determine o valor dos determinados pesos, $u_{j}$ e $v_{i}$, no intuito de maximizar o resultado, porém a atribuição é restrita a uma razão menor ou igual a um, conforme a restrição (2), sendo $u_{j}$ e $v_{i}$ maiores ou iguais à zero (3).

$\operatorname{Max} E f f o=\frac{\sum_{j=1}^{S} u_{j} y_{j o}}{\sum_{i=1}^{r} v_{i} x_{i o}}$

Sujeito a

$\frac{\sum_{j=1}^{S} u_{j} y_{j k}}{\sum_{i=1}^{r} v_{i} x_{i k}} \leq 1, \forall k$

$V_{i}, U_{j} \geq 0, \forall i, j$

Onde:

Effo- eficiência da DMU;

$u_{j}, v_{i}$ - pesos de outputs e inputs respectivamente;

$x_{i k}, y_{j k}$-inputs $i$ e outputs $j$ da DMUK;

$x_{i o}, y_{j 0}$-inputs $i$ e outputs $j$ da DMU ;

Este equacionamento matemático é definido como um problema de programação fracionária, sendo necessário igualar o denominador da função objetivo a uma constante, usualmente igual a um, a fim de solucioná-lo com o uso de programação linear. Deste modo, a nova função objetivo é descrita em 4 (Modelo Multiplicadores), aplicando as restrições de linearidade (5) e de eficiência menor ou igual a 1 (6), sendo que $u_{j}$ e $v_{i}$ respeitam a restrição de não negatividade (7).

$\operatorname{Max} E f f_{0}=\sum_{j=1}^{s} u_{j} y_{j o}$

Sujeito a

$\sum_{\substack{i=1 \\ S}}^{r} v_{i} x_{i o}=1$
$\sum_{\substack{j=1 \\ V_{i}, U_{j} \geq 0, \forall i, j}} u_{j} y_{j k}-\sum_{i=1}^{r} v_{i} x_{i k} \leq 0, \forall k$

No qual:

Effo - eficiência da DMUo;

$u_{j}, v_{i}$ - pesos de outputs e inputs respectivamente;

$X_{i k}, y_{j k}$-inputs $i$ e outputs $j$ da DMUK ;

$x_{i 0}, y_{j 0}$ - inputs $i$ e outputs $j$ da DMU0 ;

$r, s$-correspondem aos últimos inputs $i$ e outputs $j$; 
Portanto, exemplificando graficamente através da Figura 4, para a DMU T3 se tornar eficiente ela precisa reduzir seus recursos ou aumentar seus produtos. Percebe-se também através da figura que a fronteira de eficiência corresponde a uma reta e sendo assim os retornos são proporcionais (constantes).

Figura 4 - Modelo CCR

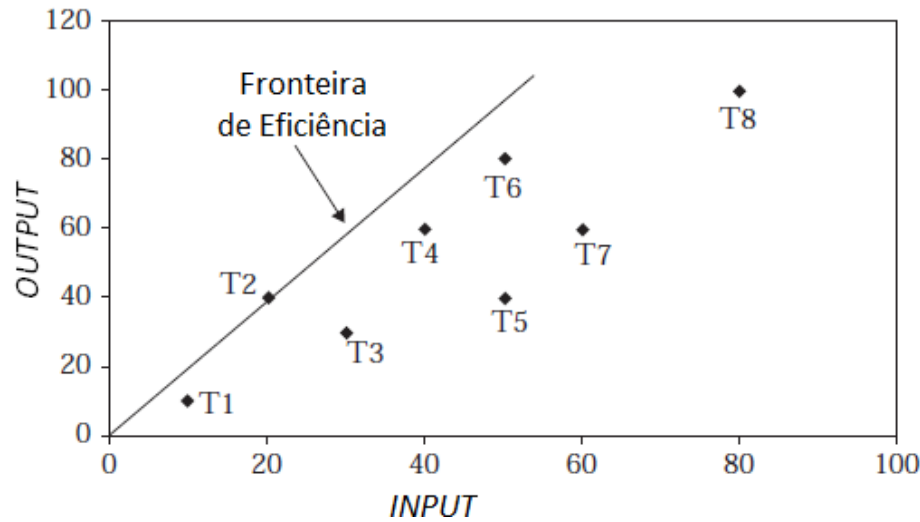

Fonte: Cullinane (2009)

O modelo apresentado até aqui é denominado, em programação linear, Primal. Para cada modelo Primal associa-se um modelo Dual. O método DEA possui os modelos Multiplicadores e Envelope com orientações a inputs e outputs, mas as análises presentes neste artigo se concentrarão na orientação por inputs dos modelos CCR e BCC.

\subsubsection{Modelo BCC}

O modelo desenvolvido por Banker, Charnes e Cooper (1984) utiliza a premissa da convexidade para obter retornos de escala variáveis na fronteira de eficiência. Guerreiro (2006) afirma que o modelo BCC "considera que um acréscimo no input poderá promover um acréscimo no output, não necessariamente proporcional, ou até mesmo um decréscimo".

Considerando a modelagem matemática no Modelo dos Multiplicadores a disparidade com o modelo CCR se dá a partir da presença da variável $u_{*}$ (8) que representa o fator variável de escala. Esta variável não atende a restrição de positividade e pode, portanto, apresentar valores negativos (11). A restrição (9) traz a linearidade ao modelo e a (10) faz com que a fronteira de eficiência respeite o limite de $100 \%$.

$\operatorname{Max} E f f_{0}=\sum_{j=1}^{s} u_{j} y_{j o}+u_{*}$

Sujeito a

$$
\begin{aligned}
& \sum_{i=1}^{r} v_{i} x_{i o}=1 \\
& \sum_{\substack{s \\
v_{i}, u_{j}}} u_{j} y_{j k}-\sum_{i=1}^{r} v_{i} x_{i k}+u_{*} \in \mathfrak{R}
\end{aligned}
$$


VI CIDESPORT/2019

Congresso Internacional

de Desempenho Portuário

No qual:

Effo - eficiência da DMU0;

$u_{j}, v_{i}$ - pesos de outputs e inputs respectivamente;

$x_{i k}, y_{j k}$-inputs $i$ e outputs $j$ da DMUK ;

$x_{i 0}, y_{j 0}$ - inputs $i$ e outputs $j$ da DMU0 ;

$r, s$-correspondem aos últimos inputs $i$ e outputs $j$;

$u_{*}-$ fator variável de escala

A Figura 5 ilustra o modelo orientado a outputs, na qual percebe-se os fatores de escala $\left(u_{*}\right)$.

Figura 5 - Modelo BCC orientado a inputs

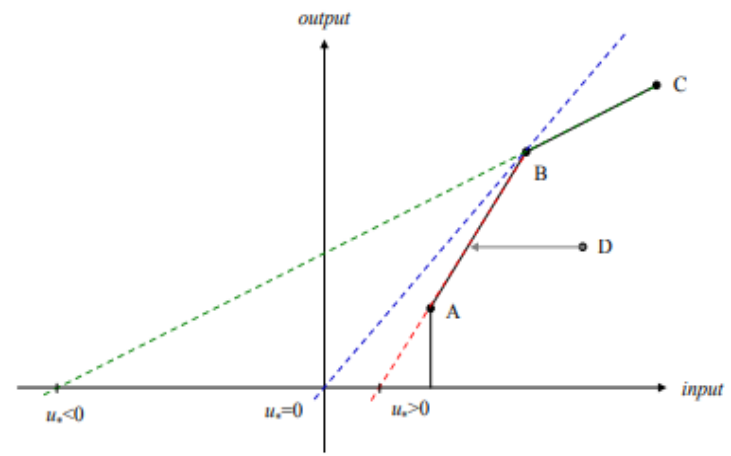

Fonte: Mello (2005)

A diferença entre os modelos CCR e BCC, de acordo com Belloni (2000), é o que o primeiro obtém um indicador de eficiencia produtiva, enquanto o desenvolvido por Banker, Charnes e Cooper obtém um indicador de eficiência técnica isolando da ineficiência produtiva a componente associada à ineficiência de escala e, portanto, apresenta a ineficiência puramente técnica, conforme a ilustração da Figura 6.

Figura 6 - Fronteira de Produção dos Modelos CCR e BCC

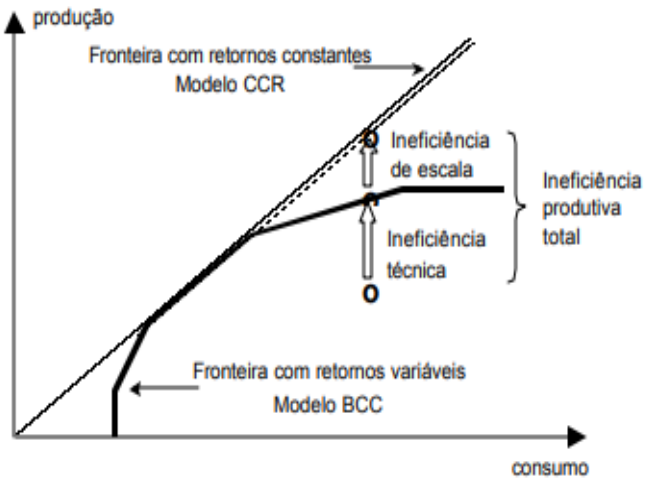

Fonte: Belloni (2000)

\subsubsection{Método da Supereficiência em DEA}

O método da Supereficiência foi desenvolvido pelos autores Adersen e Petersen, em 1993, para promover eventuais desempates entre unidades produtivas 
eficientes nas análises DEA, sem causar alterações na ordem das DMUs ineficientes (LETA et al., 2005).

A Supereficiência permite identificar dentre as unidades eficientes o quanto pode-se aumentar ou diminuir os inputs e outputs, desde que as mesmas permaneçam eficientes face às demais. Desta forma, efetua-se um ranking entre aquelas "mais eficientes" ( $100 \%$ de eficiência). Uma dada unidade em avaliação passa a ser avaliada sob a ótica de uma nova fronteira da qual não fazia parte durante a primeira análise de eficiência, comparando-a as outras DMUs eficientes (LOLLI, 2014; VALENTE, 2009).

Por exemplo, a Figura 7 ilustra três DMUs eficientes, A, B e C, de acordo com o modelo CCR orientado a inputs. Se B for retirada da análise, cria-se uma nova fronteira de eficiência conectando $A$ a $C$ e, a supereficiência de $B$ será da pela razão OB'/OB maior que um.

Figura 7 - Método da Supereficiência

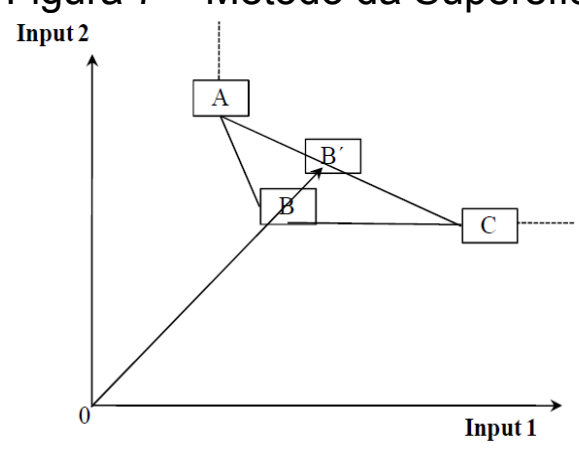

Fonte: Lovell e Rouse (2003)

A compreensão destas definições permite o desenvolvimento da próxima seção, referente aos procedimentos de seleção de recursos, produtos e DMUs a serem utilizadas neste artigo, bem como seus devidos critérios de escolha.

\section{METODOLOGIA}

\subsection{Seleção dos inputs e outputs}

A seleção dos inputs e outputs a serem utilizados neste trabalho foi determinada a partir de uma pesquisa bibliográfica para averiguar quais os dados de entrada e de saída são usualmente escolhidos neste tipo de estudo.

A técnica de pesquisa bibliográfica utilizada primeiramente foi a de revisão descritiva ou sistemática que é realizada a partir da coleta, compilação e sistematização de dados numéricos que indicam a frequência dos tópicos e métodos encontrados na literatura existente (PARÉ et Al., 2013).

A plataforma de dados utilizada para esta técnica foi a dos Periódicos da Capes. Inicialmente, as palavras-chaves pesquisadas foram: "data envelopment analysis" and "port efficiency", o que resultou em 978 trabalhos publicados, no entanto, majoritariamente, as publicações estavam voltadas a terminais de contêineres. Assim, no intuito de direcionar a pesquisas para a área de granéis, inseriram-se as seguintes palavras-chave: "data envelopment analysis" and "bulk port efficiency". A seleção dos artigos foi determinada visando análises de eficiência operacional dos portos, excluindo trabalhos que utilizassem DEA para fins não relacionados ao setor portuário e trabalhos que fossem exclusivos de outras cargas. Portanto, a seleção final contou 
VI CIDESPORT/2019

Congresso Internacional

de Desempenho Portuário

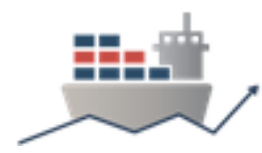

com 11 publicações, conforme a Tabela 6, que utilizaram entre suas DMUs terminais de granéis sólidos, exclusivamente ou não.

Tabela 6 - Pesquisa Sistemática

Pesquisa

Filtro

Resultados

Seleção

"data envelopment analysis" and Idiomas: Inglês, Espanhol e "port efficiency" Português

978

"data envelopment analysis" and Idiomas: Inglês, Espanhol e "bulk port efficiency" Português

234

Fonte: Elaborada pela Autora (2019)

Posteriormente, reconhecendo a dificuldade de encontrar trabalhos que selecionassem, exclusivamente, terminais de granéis sólidos realizou-se a técnica de pesquisa arbitrária que é definida por Alves (2019) como "[...] uma busca arbitrária, não sendo pré-determinada e específica, e que não busca a generalização ou compilação de publicações acerca do tema". A seleção final através das duas técnicas de pesquisa resultou na avaliação de dezessete trabalhos, dentre os quais apenas seis pesquisas foram realizadas exclusivamente em portos de granéis sólidos.

As informações de dados de entrada e saída encontradas foram analisadas e divididas em áreas. Os dados de inputs foram separados em relação à atracação das embarcações, capacidade de armazenagem dos terminais, capacidade de carregamento, mão de obra disponível e outros. As parcelas mais significativas foram atracação, armazenagem e carregamento, sequencialmente, e as porcentagens estão dispostas no Gráfico 1.

Gráfico 1 - Frequência de inputs adotados em outros estudos

\section{INPUTS}

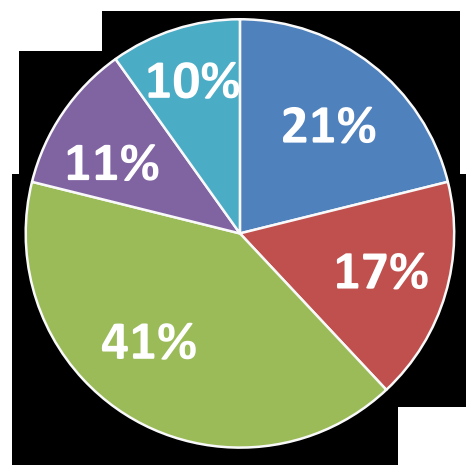

- ARMAZENAGEM

- CARREGAMENTO

- ATRACAÇÃO

- MÃO DE OBRA

- OUTROS

Fonte: Autora (2019)

Em relação aos outputs, seguindo a mesma lógica de agrupamento, os dados mais relevantes estão associados, predominantemente, ao carregamento (59\%) seguido de embarques, outros e tempo. As informações estão dispostas no Gráfico 2. 
Gráfico 2 - Frequência de outputs adotados em outros estudos

\section{OUTPUTS}

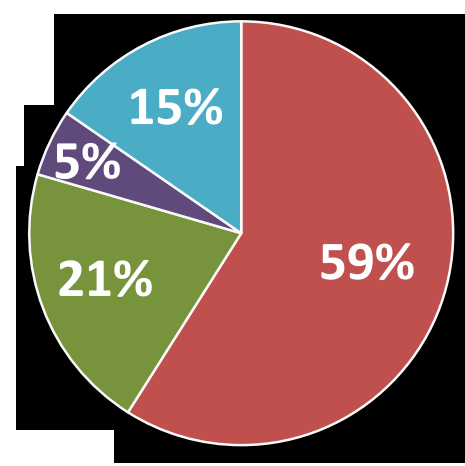

- CARREGAMENTO

- EMBARQUES

- TEMPO

- OUTROS

Fonte: Autora (2019)

A seleção dos inputs e outputs a serem utilizados no presente estudo foi determinada a partir desses subgrupos de recursos e produtos. Optou-se por selecionar quatro inputs, dois referentes à parcela de maior importância, atracação (número de berços e comprimento de berço), e dois referentes, respectivamente, à armazenagem (capacidade de armazenagem) e carregamento (prancha média). Quanto aos outputs selecionou-se, primeiramente, o carregamento anual, que correspondeu a $54 \%$ dentre os $59 \%$ do subconjunto de carregamento e, no intuito de trazer alguma singularidade a este trabalho, diferenciando-o do que é usualmente utilizado, inclui-se um segundo output relativo ao tempo operacional. A Figura 8 ilustra o fluxograma das variáveis a serem utilizadas.

Figura 8- Inputs e Outputs selecionados

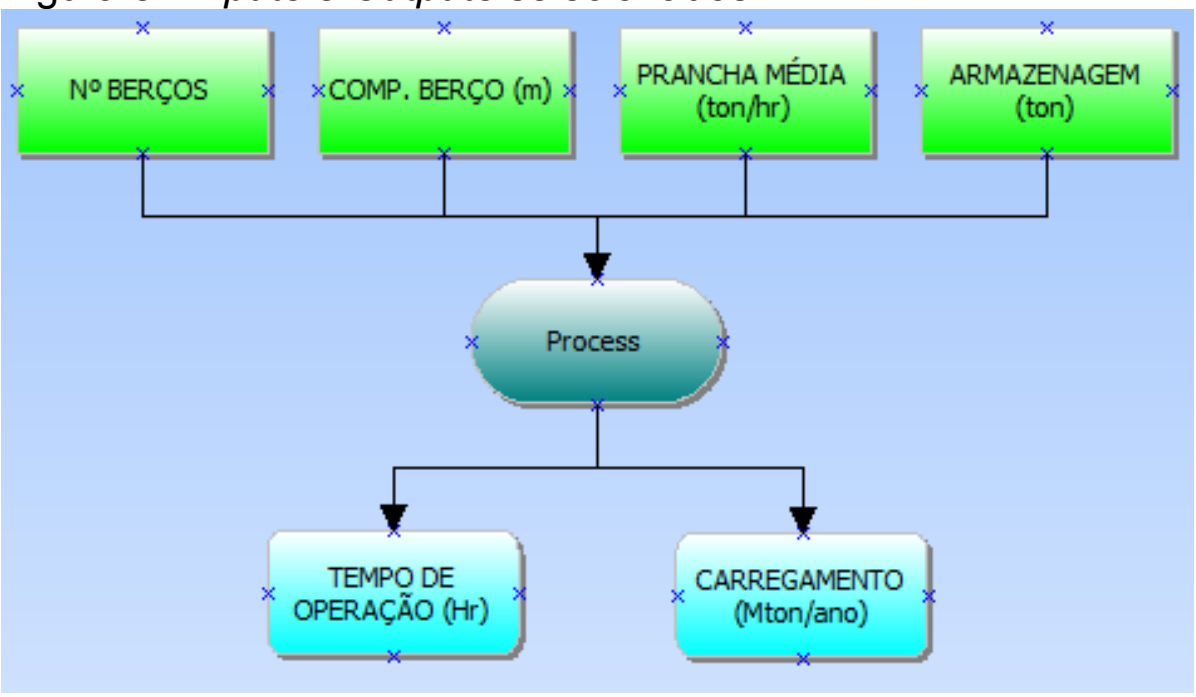

Fonte: Autora (2019)

\subsection{Seleções das DMUS e do software de análise da eficiência}

A seleção das DMUs (terminais de granéis sólidos) foi apresentada na seção 2, conforme as Tabelas 3,4 e 5, segundo as informações fornecidas pela ANTAQ 
(2018) dos principais terminais movimentadores de granéis sólidos. Realizou-se então, uma pesquisa de dados a partir dos sites dos terminais, da ANTAQ, do Laboratório de Transporte e Logística da UFSC (LabTrans) e/ou através do contato com os operadores logísticos responsáveis pelos portos. A única ausência foi em relação ao Terminal Ternium $B r$, responsável pelo terceiro maior número de toneladas de carvão desembarcadas no Brasil, para o qual não obteve-se retorno quanto ao fornecimento de dados, portanto não foi possível incluí-lo a este estudo. As Tabelas 7, 8 e 9 correspondem aos dados coletados.

Tabela 7 - Dados de Terminais de Minério de Ferro

\begin{tabular}{|c|c|c|c|c|c|c|}
\hline TERMINAL & $\begin{array}{c}\mathrm{N}^{\circ} \\
\text { BERÇOS }\end{array}$ & $\begin{array}{l}\text { COMP. } \\
\text { BERÇO } \\
(\mathrm{m})\end{array}$ & $\begin{array}{c}\text { PRANCHA } \\
\text { MÉDIA } \\
\text { (ton/hr) }\end{array}$ & $\begin{array}{c}\text { ARMAZENAGEM } \\
\text { (ton) }\end{array}$ & $\begin{array}{c}\text { TEMPO DE } \\
\text { OPERAÇÃO } \\
(\mathrm{Hr})\end{array}$ & $\begin{array}{c}\text { CARREGAMENTO } \\
\text { (Mton/ano) }\end{array}$ \\
\hline Ponta da Madeira & 5 & 520 & 7.916 & 7.200 .000 & 28,6 & 197,09 \\
\hline Itaguaí (Sepetiba) & 3 & 320 & 3.788 & 3.200 .000 & 45,4 & 48,46 \\
\hline Ilha Guaíba & 2 & 340 & 3.607 & 1.778 .000 & 58,3 & 41,18 \\
\hline Porto Sudeste do Brasil & 2 & 383 & 5.406 & 2.500 .000 & 30,3 & 10,64 \\
\hline Porto Gregório Curvo & 3 & 120 & 627 & 250.000 & 3,4 & 2,47 \\
\hline Granel Química Ladário & 3 & 60 & 525 & 700.000 & 4,7 & 0,71 \\
\hline Terminal Ponta Ubu & 3 & 308 & 699 & 1.800 .000 & 53,7 & 0,08 \\
\hline
\end{tabular}

Fonte: Autora (2019)

Tabela 8 - Dados de Terminais de Soja

\begin{tabular}{|c|c|c|c|c|c|c|}
\hline TERMINAL & $\begin{array}{c}\mathbf{N}^{\circ} \\
\text { BERÇOS }\end{array}$ & $\begin{array}{c}\text { COMP. } \\
\text { BERÇO } \\
(\mathrm{m})\end{array}$ & $\begin{array}{c}\text { PRANCHA } \\
\text { MÉDIA } \\
\text { (ton/hr) }\end{array}$ & $\begin{array}{l}\text { ARMAZENAGEM } \\
\text { (ton) }\end{array}$ & $\begin{array}{c}\text { TEMPO DE } \\
\text { OPERAÇÃO } \\
(\mathrm{Hr})\end{array}$ & $\begin{array}{c}\text { CARREGAMENTO } \\
\text { (Mton/ano) }\end{array}$ \\
\hline Santos & 8 & 276 & 868 & 585.000 & 68,6 & 15,57 \\
\hline Paranaguá & 13 & 245 & 1.037 & 1.550 .000 & 57,0 & 15,36 \\
\hline Itaqui & 1 & 280 & 1.115 & 255.000 & 56,3 & 8,54 \\
\hline Rio Grande & 6 & 350 & 1.038 & 905.000 & 52,9 & 6,56 \\
\hline São Francisco Do Sul & 2 & 276 & 852 & 364.000 & 77,6 & 5,48 \\
\hline Terminal De Tubarão & 2 & 280 & 1.258 & 442.000 & 47,0 & 4,08 \\
\hline Terminal Cotegipe & 2 & 260 & 801 & 396.000 & 81,4 & 3,78 \\
\hline Terminal Bianchini & 3 & 280 & 1.364 & 980.000 & 43,8 & 3,59 \\
\hline Tiplam & 1 & 280 & 729 & 342.500 & 82,2 & 3,30 \\
\hline Terminal Hermasa & 2 & 86 & 632 & 327.000 & 106,1 & 2,71 \\
\hline
\end{tabular}

Fonte: Autora (2019)

Tabela 9- Dados de Terminais de Carvão Mineral

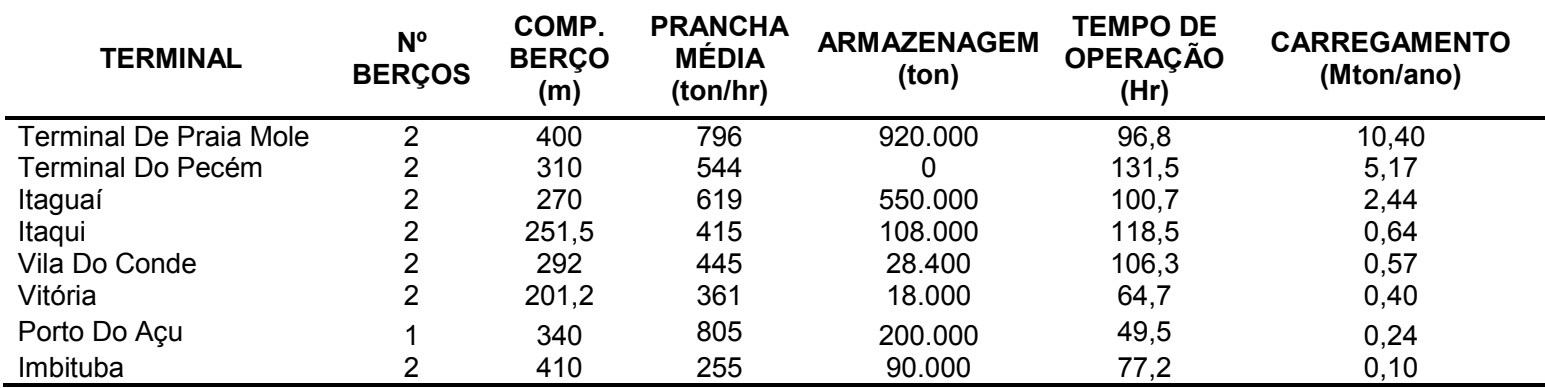

Fonte: Autora (2019)

Ao analisar as tabelas, notam-se algumas discrepâncias de dados que podem influenciar nos resultados. A primeira observação é quanto ao Terminal Marítimo Ponta Ubu, na Tabela 7, que possui uma capacidade de armazenamento de 1.800 .000 toneladas que é relativamente alta; na qual esperava-se encontrar um número menor, pois é o terminal de menor movimentação anual. Esta informação procede do 


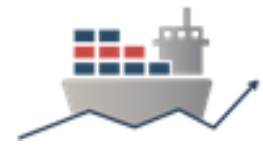

LabTrans da UFSC que auxilia na elaboração de diversos Planos de Desenvolvimentos e Zoneamentos de terminais brasileiros. A Samarco, responsável pelo terminal, foi comunicada a respeito dos dados e foi solicitado a confirmação dos mesmos, porém até o presente momento, não se obteve retorno.

A segunda observação é referente à Tabela 8 , quanto ao Terminal Portuário do Pecém que possui uma capacidade de armazenamento de carvão igual à zero, isto é devido à característica de descarregamento e transporte do terminal. Segundo informações contidas no Plano Mestre (2015) do mesmo, o descarregamento é realizado de maneira contínua por uma correia transportadora com extensão de aproximadamente $14 \mathrm{~km}$ para as usinas termoelétricas da região.

A fim de analisar a eficiência dos terminais graneleiros selecionados, optouse por utilizar um software comercial devido à praticidade de uso e, o fato de já haver uma licença adquirida pelo projeto aprovado, CNPq Universal, sob o número 441515/2014-2, sob coordenação da professora Vanina M. Durski Silva da UFSC - Joinville, sem gerar ônus adicional ao desenvolvimento deste estudo. O software selecionado para resolução da problemática utilizando o Método de Análise Envoltória de Dados (DEA) foi o Frontier Analyst versão 4.3.0. A partir da definição das DMUs, variáveis de entrada e saída e do software pode-se prosseguir para as análises de resultados.

\section{RESULTADOS}

A partir da seleção das DMUs e do software foi possível realizar a análise de resultados, a qual foi elaborada conforme os modelos DEA para dois diferentes cenários. O primeiro (Cenário $A$ ) referente aos terminais de cada produto separadamente e o segundo (Cenário B), avaliando todos os terminais no intuito de verificar se há disparidade entre terminais que embarcam e desembarcam granéis sólidos.

\subsection{Cenário $\mathrm{A}$}

\subsubsection{Terminais de Minério}

Este primeiro cenário contempla as análises realizadas entre os terminais de cada produto separadamente. A Tabela 10 expõe os resultados encontrados para os terminais de minério de ferro, na qual verifica-se que quatro terminais obtiveram eficiências máximas em ambos modelos e orientações, ou seja, tais terminais têm melhor aproveitamento de recursos e produtos. Sendo que o terminal de Gregório Curvo (MS) foi mais vezes utilizado como referência nas análises de benchmarking (15 vezes), contabilizando os quatro campos de dados - dos dois modelos e duas orientações.

Tabela 10 - Resultados para terminais de minério de ferro

\begin{tabular}{lccccc} 
TERMINAIS DE MINÉRIO & \multicolumn{2}{c}{ CCR } & \multicolumn{2}{c}{ BCC } & \multirow{2}{*}{ DE FERRO } \\
\cline { 2 - 5 } & IN & OUT & IN & OUT & \\
\hline Granel Química Ladário & $100 \%$ & $100 \%$ & $100 \%$ & $100 \%$ & 7 \\
Ilha Guaíba & $63 \%$ & $63 \%$ & $100 \%$ & $100 \%$ & 5 \\
Itaguaí & $54 \%$ & $54 \%$ & $87 \%$ & $72 \%$ & 0 \\
Ponta da Madeira & $100 \%$ & $100 \%$ & $100 \%$ & $100 \%$ & 14
\end{tabular}


VI CIDESPORT/2019

Congresso Internacional

de Desempenho Portuário

\begin{tabular}{lccccc} 
Porto Do Açu & $19 \%$ & $19 \%$ & $100 \%$ & $100 \%$ & 2 \\
TERMINAIS DE MINÉRIO & \multicolumn{2}{c}{ CCR } & \multicolumn{2}{c}{ BCC } & \multirow{2}{*}{ Denchmarking } \\
\cline { 2 - 5 } \multicolumn{1}{c}{ DE FERRO } & IN & OUT & IN & OUT & \\
\hline Porto Gregório Curvo & $100 \%$ & $100 \%$ & $100 \%$ & $100 \%$ & 15 \\
Porto Sudeste do Brasil & $29 \%$ & $29 \%$ & $100 \%$ & $100 \%$ & 2 \\
Terminal Ponta Ubu & $6 \%$ & $6 \%$ & $98 \%$ & $6 \%$ & 0 \\
Tubarão & $100 \%$ & $100 \%$ & $100 \%$ & $100 \%$ & 9 \\
\hline
\end{tabular}

Fonte: Autora (2019)

O software fornece as contribuições dos input/output sobre os resultados de cada terminal, variando de 0 a 100 , sendo que valores positivos representam interdependências com os resultados e nulos equivalem a quais dados foram ignorados.

Considerando os terminais de maior eficiência (Granel Química Ladário, Ponta da Madeira, Gregório Curvo e Tubarão), os índices de correlação, fornecidos pelo software, estão dispostos na Tabela 11. A respeito destes índices, o software não fornece os valores dos pesos de cada variável utilizados no cálculo de eficiência, o que o mesmo fornece é uma correlação, em porcentagem, dos inputs e outputs sobre os resultados encontrados.

Nota-se, Tabela 11, que o output carregamento anual foi utilizado por todas as quatro DMUs. Tubarão e Ponta da Madeira apresentam preponderância nos dados de carregamento anual (Tabela 7) o que explica a valorização desta saída para o cálculo de eficiência das mesmas. Já Gregório Curvo e Granel Química Ladário, apresentam os menores tempos operacionais conforme a Tabela 7, por isso obtémse altos valores de correlação. Vale salientar que para o output de tempo de operação, a eficiência é calculada de maneira inversa, pois quanto menor for este valor, mais eficiente será um terminal.

Tabela 11 - Índices de correlação para terminais mineraleiros

\begin{tabular}{clcccc} 
Terminais & $\begin{array}{c}\text { Gregório } \\
\text { Curvo }\end{array}$ & Tubarão & $\begin{array}{c}\text { Granel Química } \\
\text { Ladário }\end{array}$ & $\begin{array}{c}\text { Ponta da } \\
\text { Madeira }\end{array}$ \\
\hline \multirow{2}{*}{ Inputs } & $\mathbf{N}^{\circ}$ de Berço & 0 & 81,6 & 0 & 0 \\
& Comp. Berço & 91,7 & 0 & 99,9 & 0 \\
& Prancha-média & 0 & 0 & 0 & 49,7 \\
& Armazenagem & 8,2 & 18,3 & 0 & 50,2 \\
\hline \multirow{2}{*}{ Outputs } & Tempo de Operação & 92,1 & 9,3 & 96,9 & 0 \\
& Carregamento Anual & 7,8 & 90,6 & 3 & 99,9 \\
\hline
\end{tabular}

Fonte: Autora (2019)

No intuito de se obter um ranking entre as unidades tomadoras de decisão e diferenciar as que atingiram Effo=1, utilizou-se o conceito de supereficiência, que segundo Valente (2009), "consiste na análise individual de cada DMU quando excluída do conjunto de observações de referência da DEA". Deste modo, caso seja orientada por inputs, a DMU poderá aumentar os recursos alocados e ainda assim se manter eficiente; a disposição deste ranking está na Tabela 12. 
VI CIDESPORT/2019

Congresso Internacional

de Desempenho Portuário

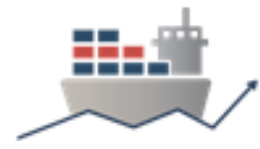

Tabela 12 - Ranking de terminais de minério

\begin{tabular}{clc} 
Ranking & \multicolumn{1}{c}{ Terminais } & Supereficiência \\
\hline 1 & Porto Gregório Curvo & $400,30 \%$ \\
2 & Tubarão & $156,60 \%$ \\
3 & Granel Química Ladário & $144,70 \%$ \\
4 & Ponta da Madeira & $143,00 \%$ \\
5 & Ilha Guaíba & $63,00 \%$ \\
6 & Itaguaí & $53,70 \%$ \\
7 & Porto Sudeste do Brasil & $29,10 \%$ \\
8 & Porto Do Açu & $19,10 \%$ \\
9 & Terminal Ponta Ubu & $6,30 \%$ \\
\hline
\end{tabular}

Fonte: Autora (2019)

A respeito destes resultados é interessante averiguar que dois portos fluviais, Gregório Curvo e Granel Química Ladário, estão dentre as quatro primeiras colocações. Os dois terminais estão localizadas na Hidrovia Paraguai-Paraná no estado do Mato Grosso do Sul e são abastecidos por cargas provenientes do transporte ferroviário. As principais variáveis que contribuíram para os altos resultados de eficiência foram o comprimento de berço e tempo de operação, apresentando valores inferiores em relação aos demais terminais (Tabela 7).

As quatro DMUs de pior desempenho (Itaguaí, Porto Sudeste do Brasil, Porto do Açu e Terminal Ponta Ubu) foram analisadas de forma individual quanto aos possíveis potenciais de melhorias, tal informação também é fornecida pelo software. A Tabela 13 expõe os potenciais de melhoria para o Terminal Marítimo Ponta Ubu.

Tabela 13 - Potenciais de melhoria para o Terminal Marítimo Ponta Ubu

\begin{tabular}{lcc} 
Terminal Ponta Ubu & Encontrado & Proposto \\
\hline CARREGAMENTO (Mton/ano) & 0,08 & 0,16 \\
No BERÇOS (unid) & 3,00 & 0,19 \\
TEMPO DE OPERAÇÃO (hr) & 53,70 & 53,7 \\
COMP. BERÇO (m) & 308,00 & 7,60 \\
PRANCHA MÉDIA (ton/hr) & 699,00 & 39,70 \\
ARMAZENAGEM (ton) & $1.800 .000,00$ & $15.829,00$ \\
\hline
\end{tabular}

Fonte: Autora (2019)

A correta interpretação dos dados exige uma comparação com a realidade enfrentada pelos portos, como por exemplo: não é possível tornar a quantidade de berços em um número não inteiro ou, a diminuição drástica do comprimento de berço, impossibilitaria a atracação de navios. Portanto, a proposta mais adequada aos terminais seria reduzir a capacidade de armazenagem, o que também poderia causar um impacto positivo sobre o tempo operacional. De acordo com uma conversa via telefone com o especialista responsável pela área operacional do Porto de Vitória, geralmente o pátio de estocagem é utilizado por muitos operadores logísticos, o que ocasiona atrasos nos processos de carregamento e aumenta a demurrage sobre os navios; diminuir a capacidade de armazenagem ou realoca-la em uma área externa ao terminal pode contribuir para redução do tempo de carregamento.

Conforme os resultados calculados pelo método, as proposições quanto à redução das capacidades de armazenamento dos quatro terminais de pior 
VI CIDESPORT/2019

Congresso Internacional

de Desempenho Portuário

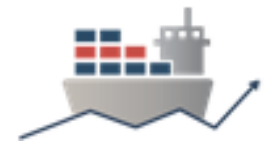

desempenho (Itaguaí, Porto Sudeste do Brasil, Porto do Açu e Terminal Ponta Ubu) estão dispostas na Tabela 14 .

Tabela 14 - Potenciais de melhoria para terminais pouco eficientes

\begin{tabular}{lcc}
\multicolumn{1}{c}{ Terminais } & Encontrado (ton) & Proposto (ton) \\
\hline Terminal Marítimo Ponta Ubu & 1.800 .000 & 15.829 \\
Porto Do Açu & 3.200 .000 & 1.718 .555 \\
Porto Sudeste do Brasil & 2.500 .000 & 405.623 \\
Itaguaí & 3.200 .000 & 1.718 .555 \\
\hline
\end{tabular}

Fonte: Autora (2019)

No entanto, apenas com o Método DEA não é possível investigar estas informações a fundo; sendo necessário um estudo direcionado para avaliar a situação de cada terminal. Algumas ponderações podem ser feitas, por exemplo, como já mencionado na seção 2 , uma pequena capacidade de armazenagem pode resultar no aumento do tempo de espera de navios, e grandes dimensões de pátio dificultam a recuperação do investimento, por isso cada terminal deve buscar um tamanho de pátio de armazenagem ótimo que atenda a suas necessidades, evitando o super ou subdimensionamento.

\subsubsection{Terminais de soja}

Em seguida foi realizada a análise dos terminais de soja, ver Tabela 15, os quais apresentaram menores discrepâncias de eficiência e maiores quantidades de DMUs com eficiências ótimas, totalizando 8 entre as 10 listadas.

Tabela 15 - Resultados para terminais de soja

\begin{tabular}{lccccc}
\multirow{2}{*}{\multicolumn{1}{c}{ TERMINAIS DE SOJA }} & \multicolumn{2}{c}{ CCR } & \multicolumn{2}{c}{ BCC } & \multirow{2}{*}{ Benchmarking } \\
\cline { 2 - 5 } & IN & OUT & IN & OUT & \\
\hline Itaqui & $100 \%$ & $100 \%$ & $100 \%$ & $100 \%$ & 10 \\
Paranaguá & $100 \%$ & $100 \%$ & $100 \%$ & $100 \%$ & 4 \\
Rio Grande & $100 \%$ & $100 \%$ & $100 \%$ & $100 \%$ & 10 \\
Santos & $100 \%$ & $100 \%$ & $100 \%$ & $100 \%$ & 8 \\
São Francisco Do Sul & $91 \%$ & $91 \%$ & $94 \%$ & $92 \%$ & 0 \\
Terbian - Terminal Bianchini & $100 \%$ & $100 \%$ & $100 \%$ & $100 \%$ & 4 \\
Terminal De Tubarão - TPD & $100 \%$ & $100 \%$ & $100 \%$ & $100 \%$ & 11 \\
Terminal Hermasa & $100 \%$ & $100 \%$ & $100 \%$ & $100 \%$ & 8 \\
Terminal Cotegipe & $90 \%$ & $90 \%$ & $93 \%$ & $92 \%$ & 0 \\
Tiplam & $100 \%$ & $100 \%$ & $100 \%$ & $100 \%$ & 12 \\
\hline Fonannnnnnn & & & & & \\
\hline
\end{tabular}

Fonte: Autora (2019)

Realizando a análise com orientação para inputs no modelo de retorno constante para os terminais de Cotegipe e São Francisco do Sul (SFS), verifica-se, Tabela 16, que as variáveis que exercem maiores influências sobre os resultados destes terminais são prancha média e tempo de operação. 
VI CIDESPORT/2019

Congresso Internacional

de Desempenho Portuário

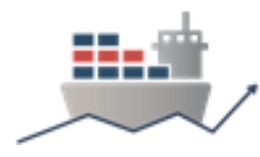

Tabela 16 - Correções de variáveis para Cotegipe e SFS

\begin{tabular}{clcc} 
& \multicolumn{1}{c}{ Terminais } & SFS & Cotegipe \\
\hline \multirow{4}{*}{ Inputs } & $\mathbf{N}^{\circ}$ de Berço & 4,8 & 5,1 \\
& Comp. Berço & 0 & 0 \\
& Prancha-média & 94,3 & 93,4 \\
& Armazenagem & 1 & 1,2 \\
\hline \multirow{2}{*}{ Outputs } & Tempo de Operação & 93,2 & 95,2 \\
& Carregamento & 6,1 & 4,4 \\
\hline
\end{tabular}

Fonte: Autora (2019)

A sugestão de potencial melhoria considera realizar um incremento no volume embarcado de $10,88 \%$ e $10,01 \%$ para Cotegipe e SFS, respectivamente, e uma redução de aproximadamente $10 \%$ no tempo de operação dos dois terminais, conforme a Tabela 17.

Tabela 17 - Proposta de Melhorias

Potencial de Melhoria Para Carregamento Anual

\begin{tabular}{|c|c|c|c|}
\hline Terminais & Encontrado (Mton) & Proposto (Mton) & $\%$ de Melhoria \\
\hline Terminal Cotegipe & 3,78 & 4,19 & $10,88 \%$ \\
\hline São Francisco Do Sul & 5,48 & 6,03 & $10,01 \%$ \\
\hline \multicolumn{4}{|c|}{ Potencial de Melhoria Para Tempo de Operação } \\
\hline Terminais & Encontrado (Hr) & Proposto (Hr) & $\%$ de Melhoria \\
\hline Terminal Cotegipe & 77,6 & 70,616 & $-9,00 \%$ \\
\hline São Francisco Do Sul & 81,4 & 73,26 & $-10,00 \%$ \\
\hline
\end{tabular}

Fonte: Autora (2019)

Percebe-se que quanto à capacidade de armazenamento, não são necessárias melhorias visto que todos os terminais de soja considerados estão bem dimensionados, mesmo havendo uma condicionante a mais para terminais de grãos que é o efeito da sazonalidade, provocando maiores movimentações nos terminais em determinados períodos do ano.

Novamente, utilizando o conceito de superficiência para a primeira coluna de eficiência, obteve-se o ranking das melhores DMUs, conforme a Tabela 18, na qual o Porto de Itaqui apresentou a maior folga quanto a aumentar seus inputs e mesmo assim, permanecer eficiente.

Tabela 18 - Ranking de terminais de soja

\begin{tabular}{clc} 
Ranking & \multicolumn{1}{c}{ Terminais } & Supereficiência \\
\hline 1 & Itaqui & $285 \%$ \\
2 & Santos & $176 \%$ \\
3 & Terminal Hermasa & $139 \%$ \\
4 & Paranaguá & $118 \%$ \\
5 & Rio Grande & $108 \%$ \\
6 & Terminal De Tubarão - & $107 \%$ \\
7 & TPD & $101 \%$ \\
8 & Terbian - Bianchini & $101 \%$
\end{tabular}


VI CIDESPORT/2019

Congresso Internacional

de Desempenho Portuário

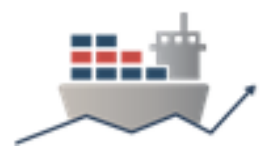

\begin{tabular}{clc} 
Ranking & \multicolumn{1}{c}{ Terminais } & Supereficiência \\
\hline 9 & São Francisco Do & $91 \%$ \\
10 & Sul & Terminal Cotegipe \\
\hline
\end{tabular}

Fonte: Autora (2019)

\subsubsection{Terminais de Carvão}

$\mathrm{Na}$ sequência, o estudo de portos de carvão foi realizado e partir das correlações input/output é possível perceber uma preponderância dos dados de prancha média e carregamento anual sobre os cálculos de eficiência (Tabela 19), mesmo existindo diferenças significativas como entre os terminais de Imbituba (255 ton/hr) e Porto do Açu (805 ton/hr), (Tabela 9).

Tabela 19 - Índices de interdependência para terminais de carvão

\begin{tabular}{clccccc}
\multicolumn{1}{c}{ Terminais } & Imbituba & Açu & $\begin{array}{c}\text { Praia } \\
\text { Mole }\end{array}$ & Pecém & Vitória \\
\hline \multirow{4}{*}{ Inputs } & $N^{\circ}$ de Berço & 0 & 0 & 0 & 0 & 0 \\
& Comp. Berço & 0 & 0 & 0 & 0 & 99,9 \\
& Prancha-média & 99,9 & 99,9 & 99,9 & 99,9 & 0 \\
& Armazenagem & 0 & 0 & 0 & 0 & 0 \\
\hline \multirow{2}{*}{ Outputs } & Tempo de Operação & 99,9 & 98,6 & 0 & 0 & 0 \\
& Carregamento & 0 & 1,1 & 99,9 & 99,9 & 99,9 \\
\hline
\end{tabular}

Fonte: Autora (2019)

Nota-se na Tabela 20, que cinco terminais obtiveram eficiências iguais a um e que os terminais Porto do Açu e Vitória foram as maiores referências na análise de benchmarking, ou seja, é possível que na construção da fronteira de eficiência as DMUs ineficientes estavam localizadas abaixo da fronteira, mas próximas a estes terminais, por isso foram mais vezes utilizados na análise comparativa.

Tabela 20 - Resultados para terminais de carvão

\begin{tabular}{lccccc}
\multirow{2}{*}{$\begin{array}{c}\text { TERMINAIS DE } \\
\text { CARVÃO }\end{array}$} & \multicolumn{2}{c}{ CCR } & \multicolumn{2}{c}{ BCC } & Benchmarking \\
\cline { 2 - 5 } & IN & OUT & IN & OUT & \\
\hline Imbituba & $100 \%$ & $100 \%$ & $100 \%$ & $100 \%$ & 5 \\
Itaguaí & $70 \%$ & $70 \%$ & $95 \%$ & $70 \%$ & 0 \\
Itaqui & $55 \%$ & $55 \%$ & $96 \%$ & $55 \%$ & 0 \\
Porto Do Açu & $100 \%$ & $100 \%$ & $100 \%$ & $100 \%$ & 16 \\
Terminal Praia Mole & $100 \%$ & $100 \%$ & $100 \%$ & $100 \%$ & 11 \\
Terminal Do Pecém & $100 \%$ & $100 \%$ & $100 \%$ & $100 \%$ & 9 \\
Vila Do Conde & $61 \%$ & $61 \%$ & $96 \%$ & $63 \%$ & 0 \\
Vitória & $100 \%$ & $100 \%$ & $100 \%$ & $100 \%$ & 16 \\
\hline
\end{tabular}

Fonte: Autora (2019)

A análise da supereficiência indicou que a DMU mais eficiente foi o Terminal Portuário do Pecém (Tabela 21), que poderia incrementar em $1.000 \%$ seus inputs e continuar eficiente. Obviamente, não é de interesse de nenhum porto aumentar seus recursos sem necessidade, contudo, o cálculo de supereficiência é baseado na folga que os terminais teriam para aumentar variáveis de entrada, caso o modelo seja 
VI CIDESPORT/2019

Congresso Internacional

de Desempenho Portuário

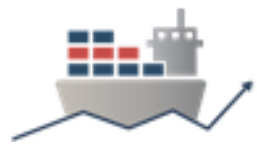

orientado a inputs ou de diminuir saídas, caso seja orientado a ouputs. A intenção é encontrar uma maneira de ordenar os terminais em um ranking e não, de promover sugestões de melhorias baseada nestas informações.

Tabela 21 - Ranking de terminais de carvão

\begin{tabular}{clc} 
Ranking & \multicolumn{1}{c}{ Terminais } & Supereficiência \\
\hline 1 & Terminal Do Pecém & $1000 \%$ \\
2 & Porto Do Açu & $261 \%$ \\
3 & Vitória & $260 \%$ \\
4 & Terminal Praia Mole & $201 \%$ \\
5 & Imbituba & $119 \%$ \\
6 & Itaguaí & $70 \%$ \\
7 & Vila Do Conde & $61 \%$ \\
8 & Itaqui & $55 \%$ \\
\hline
\end{tabular}

Fonte: Autora (2019)

Ainda quanto ao terminal do Pecém, era esperado que a armazenagem tivesse forte interdependência com os resultados (Tabela 19), visto que o valor desta entrada é nulo e um diferencial comparado aos demais, porém este item não foi contabilizado na análise de eficiência e sim, de forma expressiva, na de supereficiência.

As melhorias propostas foram baseadas no gráfico da Figura 9, que expõe o potencial geral de melhorias em cada variável (input e output). Segundo o mesmo, os outputs de maior significância para aumentar o percentual de eficiência são tempo de operação e carregamento anual, que poderiam ter uma redução e incremento médio de $-26,74 \%$ e $43,68 \%$, respectivamente.

Figura 9 - Potencial geral de melhorias para terminais de carvão

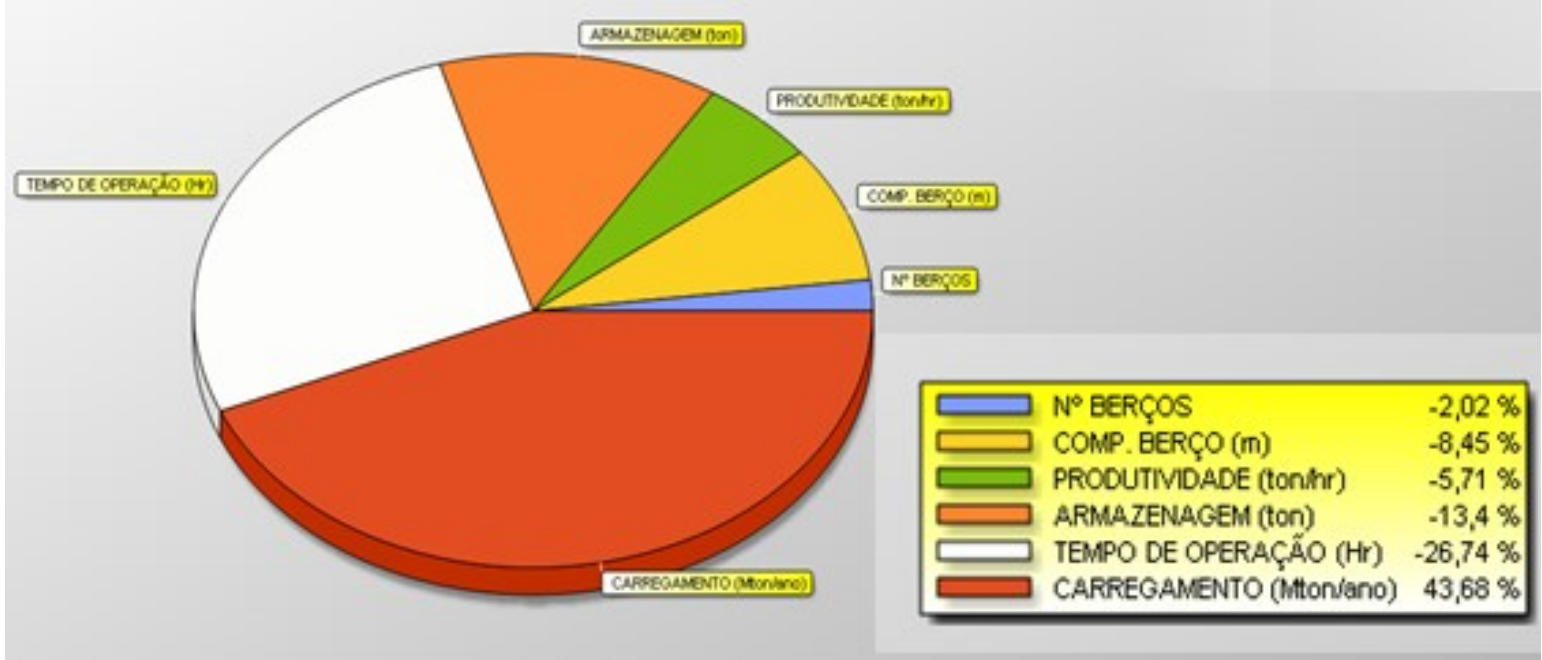

Fonte: Software Frontier Analyst (2019)

\subsection{Cenário B}

Os autores Oliveira e Cariou (2011) afirmaram que existem diferenças significativas entre portos de carga e descarga (importam/exportam mercadorias), principalmente em taxas de carregamento. Baseando-se nesta afirmação, propõe-se 


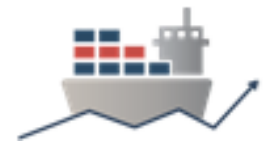

- cenário $\mathrm{B}$, criado para avaliar a influência a cerca dos processos de carregamento/descarregamento de navios na eficiência de terminais.

Como já mencionado, geralmente a descarga é realizada por equipamentos tipo Grab (descontínuo) o que provoca menores números de prancha média. Esta informação pode ser comprovada analisando os dados de entrada de cada terminal quanto ao carregamento/descarregamento (ton/hr) na Tabela 22. Ordenando os valores encontrados em ordem crescente, sem identificar os terminais (linhas), e utilizando uma escala de cores (na qual, verde representa maiores valores de prancha média e vermelho, menores) nota-se que os terminais de carvão não apresentaram valores acima de 900 ton/hr.

Tabela 22 - Prancha média (ton/hr) dos terminais

\begin{tabular}{ccc} 
Minério & Soja & Carvão \\
\hline 525 & 632 & 255 \\
627 & 729 & 361 \\
699 & 801 & 415 \\
3.607 & 852 & 445 \\
3.788 & 868 & 544 \\
5.179 & 1.037 & 619 \\
5.299 & 1.038 & 796 \\
5.406 & 1.115 & 805 \\
7.916 & 1.258 & \\
\hline & 1.364 & \\
\hline
\end{tabular}

Fonte: Autora (2019)

A construção do ranking, Tabela 23 , foi realizada a partir do modelo de eficiência produtiva com orientação a inputs, da análise de supereficiência e de bechmarking. A unidade produtiva mais supereficiente foi o Terminal do Pecém responsável pela importação de carvão; dado os relativos baixos valores de prancha média para terminais que importam mercadorias, este primeiro lugar no ranking com todas as DMUs (carvão, minério e soja) poderia gerar certa estranheza. Mas, com o auxílio da observação realizada na seção 3 , este resultado pode ser justificado.

O descarregamento realizado no Terminal Portuário do Pecém é de modo contínuo através de um equipamento de capacidade de $2.400 \mathrm{ton} / \mathrm{hr}$, segundo dado da VLI (empresa responsável pelas operações logística do porto). Além disso, a capacidade de armazenamento do terminal é nula, pelo fato de haver correias transportadoras com extensão de 13,7 km que conduzem o carvão até usinas termoelétricas da região que irão consumir este produto, justificando a não necessidade de se manter armazenagem no terminal. Acredita-se que estas informações de entradas exerçam forte influência sobre os resultados encontrados.

Tabela 23 - Ranking de todos os terminais

\begin{tabular}{|c|c|c|c|c|c|}
\hline Ranking & Produto & Terminais & Supereficiência & CCR & Benchmarking \\
\hline 1 & Carvão & Terminal Do Pecém & $1000 \%$ & $100 \%$ & 7 \\
\hline 2 & Minério & Porto Gregório Curvo & $365 \%$ & $100 \%$ & 23 \\
\hline 3 & Minério & Tubarão & $149 \%$ & $100 \%$ & 12 \\
\hline 4 & Minério & Granel Química Ladário & $145 \%$ & $100 \%$ & 1 \\
\hline
\end{tabular}




\begin{tabular}{cclccc} 
Ranking & Produto & Terminais & Supereficiência & CCR & Benchmarking \\
\hline 5 & Minério & Ponta da Madeira & $143 \%$ & $100 \%$ & 16 \\
6 & Soja & Santos & $85 \%$ & $85 \%$ & - \\
7 & Soja & Itaqui & $73 \%$ & $14 \%$ & - \\
8 & Minério & Ilha Guaíba & $63 \%$ & $63 \%$ & - \\
9 & Soja & Paranaguá & $62 \%$ & $62 \%$ & - \\
10 & Carvão & Vitória & $60 \%$ & $60 \%$ & - \\
11 & Carvão & Terminal Praia Mole & $54 \%$ & $54 \%$ & - \\
12 & Minério & Itaguaí & $54 \%$ & $54 \%$ & - \\
13 & Soja & São Francisco Do Sul & $37 \%$ & $37 \%$ & - \\
14 & Minério & Porto Sudeste do & $29 \%$ & $29 \%$ & - \\
15 & Soja & Rio Grande & $29 \%$ & $29 \%$ & - \\
16 & Soja & Terminal Cotegipe & $27 \%$ & $27 \%$ & - \\
17 & Soja & Tiplam & $26 \%$ & $26 \%$ & - \\
18 & Carvão & Vila Do Conde & $24 \%$ & $24 \%$ & - \\
19 & Soja & Terminal Hermasa & $24 \%$ & $24 \%$ & - \\
20 & Soja & Terminal Tubarão & $23 \%$ & $23 \%$ & - \\
21 & Soja & Porto Do Açu & $21 \%$ & $21 \%$ & - \\
22 & Minério & Porto Do Açu & $19 \%$ & $19 \%$ & - \\
23 & Carvão & Itaguaí & $19 \%$ & $19 \%$ & - \\
24 & Carvão & Itaqui & $14 \%$ & $14 \%$ & - \\
25 & Soja & Terbian Bianchini & $14 \%$ & $14 \%$ & - \\
26 & Carvão & Imbituba & $12 \%$ & $12 \%$ & - \\
27 & Minério & Terminal Ponta Ubu & $6 \%$ & $6 \%$ & - \\
\hline
\end{tabular}

Fonte: Autora (2019)

Embora o Terminal do Pecém tenha obtido uma supereficiência notória $(1.000 \%)$, o porto que teve maior frequência no bechmarking geral foi o Porto Gregório Curvo responsável pelo embarque de minério de ferro, seguido pelo Terminal de Ponta da Madeira e de Tubarão, também mineraleiros. A respeito dos dados de eficiência, nota-se ao avaliar os dez primeiros colocados, que os terminais que exportam minério foram preponderantes e quanto aos vinte primeiros, os terminais de soja obtiveram uma maior quantidade de portos desta seleção (Tabela 24).

Tabela 24 - Quantidade de terminais melhores colocados por mercadoria

\begin{tabular}{ccc} 
Terminais & $\begin{array}{c}\text { Entre os 10 } \\
\text { primeiros }\end{array}$ & $\begin{array}{c}\text { Entre os 20 } \\
\text { primeiros }\end{array}$ \\
\hline Carvão & 2 & 4 \\
Minério & 5 & 7 \\
Soja & 3 & 9 \\
\hline
\end{tabular}

Fonte: Autora (2019)

De certa forma, identifica-se uma sensível superioridade de eficiência de terminais exportadores diante dos importadores, porém é necessário um estudo com um maior número de DMUs para de fato verificar esta tendência. Outra observação a 


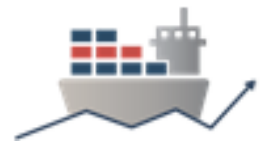

respeito disto, é que em números de movimentação destes granéis, o Brasil mais exporta do que importa, por isso é compreensível que os terminais de minério de ferro e soja tenham valores superiores de entrada e saída, sugerindo-se que terminais importadores não têm como objetivo primário o foco em operações de descarga, justificando a baixa eficiência operacional. A exemplo disto, têm-se os terminais de Itaqui (movimentador de carvão e soja) e Itaguaí (movimentador de carvão e minério de ferro), que apresentaram eficiência relativamente superiores nas mercadorias soja e minério de ferro em relação ao carvão, conforme a Tabela 23.

\section{CONSIDERAÇÕES FINAIS}

Neste artigo, foram estimados os índices de eficiência dos principais terminais de granéis sólidos brasileiros e avaliadas as possíveis variáveis que exercem influência sobre a eficiência dos mesmos. A utilização da Análise Envoltória de Dados foi escolhida por ser um método de simples aplicação e uma boa ferramenta de auxílio para o cálculo de eficiências técnica e produtiva.

O estudo foi realizado em sete etapas: a primeira consistiu-se em uma pesquisa sistemática para encontrar, a partir de trabalhos existentes, as variáveis frequentemente utilizadas no estudo de terminais portuários. Na etapa seguinte, selecionou-se tais variáveis e optou-se por adicionar mais um output relacionado ao tempo operacional dos terminais. As etapas três e quatro contemplam busca de dados e seleção de software para realização da análise da eficiência e puderam ser realizadas de maneira simultânea; já as etapas finais foram respectivamente, a criação de cenários, o processamento dos dados e análise de resultados.

Os resultados foram gerados a partir dos diferentes modelos e orientações, conforme encontrado na literatura e no intuito de diferenciar as DMUs com eficiências ótimas utilizou-se o conceito de supereficiência, propiciando a criação de rankings de eficiência entre os terminais. Através dos dados gerados pelo software durante a análise, também foi possível encontrar as correlações input/output e os potenciais de melhorias para as DMUs de menor eficiência. Vale salientar que a respeito das sugestões de melhorias o método DEA oferece uma visão geral e relativa no sentido de comparação entre as unidades tomadoras de decisão; para melhores proposições é recomendado um estudo específico para cada terminal.

A análise realizada entre todos os terminais catalogados no estudo indicou o Terminal Portuário do Pecém, que tem como mercadoria movimentada o carvão, como sendo o mais supereficiente, e dado que as pranchas médias de terminais que descarregam granéis são relativamente baixas em comparação aos que embarcam, esperava-se que algum dos terminais exportadores alcançasse a primeira colocação. Contudo, o fato do mesmo não possuir armazéns ou pátios de estocagem, favoreceu os resultados, já que a análise de supereficiência verifica o quanto uma DMU pode aumentar seus recursos e permanecer eficiente. Neste caso, o Terminal do Pecém tem uma folga significativa para o aumento da variável de capacidade de armazenamento.

Em relação ao comparativo de eficiência entre terminais exportadores versus importadores foi possível identificar uma tendência a favor dos terminais que exportam mercadorias, porém esta informação poderia ser melhor verificada a partir do estudo de mais DMUs. Posto que o Brasil mais exporta que importa granéis sólidos, é interessante avaliá-lo com outros terminais que são importantes consumidores destes produtos. 
À luz dos resultados obtidos e informações expostas, pôde-se verificar que o modelo proposto apresentou resultados coerentes e satisfatórios. As análises de potenciais de melhorias podem auxiliar em processos de tomada de decisão por parte de operadores logísticos e autoridades portuárias, quanto melhor alocação/distribuição de inputs e outputs.

Conclui-se que os objetivos propostos foram atingidos e que os resultados encontrados pelo método DEA constituem uma boa ferramenta para verificar os terminais de granéis sólidos mais eficientes do Brasil, analisar quais DMUs servem de parâmetro e quais podem incrementar melhorias.

\section{REFERÊNCIAS}

ALVES, Carlos Frederico. AVALIAÇÃO DA EFICIÊNCIA DE TERMINAIS DE CONTÊINERES: UMA APLICAÇÃO DO MÉTODO DEA COM A INCLUSÃO DE UM INSUMO INTANGÍVEL. 2019. 246 f. Monografia (Especialização) - Curso de Engenharia de Transportes e Gestão Territorial, Universidade Federal de Santa Catarina, Florianópolis, 2019. Cap. 106.

ANTAQ. ANUÁRIO 2018. Disponível em: <http://web.antaq.gov.br/ANUARIO/>. Acesso em: 05 jun. 2019.

BELLONI, José Angelo. Uma Metodologia de Avaliação da Eficiência Produtiva de Universidades Federais Brasileiras.2000. 246 f. Monografia (Especialização) Curso de Engenharia de Produção, Universidade Federal de Santa Catarina, Florianópolis, 2000. Disponível em:

$<$ https://repositorio.ufsc.br/xmlui/bitstream/handle/123456789/78457/153160.pdf?seq \%20uence=1\&isAllowed=y>. Acesso em: 10 abr. 2019.

Cooper, W.W., Park, K.S., Yu, G., 1999. IDEA and ARIDEA: Models for dealing with imprecise data in DEA. Management Science 45, 597-607.

DEVELOPMENT, United Nations Conference On Trade And. REVIEW OF MARITIME TRANSPORT. 2017. Disponível em:

<https://unctad.org/en/PublicationsLibrary/rmt2017_en.pdf?user=46>. Acesso em: 02 nov. 2018.

FARRELL, M. J. The Measurement of Productive Efficiency. Journal Of The Royal Statistical Society. Cambridge, v. 3, n. 120, p.1-38, 1957. Disponível em: < https://www.jstor.org/stable/2343100?read-now=1\&seq=1\#page_scan_tab_contents >. Acesso em: 02 nov. 2018.

FIGUEIREDO, G. S. O Papel dos Portos Concentradores na Cadeia Logística Global. Anais do XXI Encontro Nacional de Engenharia de Produção Bahia, 2001. FORUM, World Economic. Disponível em:

<http://www.abepro.org.br/biblioteca/ENEGEP2001_TR11_0464.pdf>. Acesso em: 03 jun. 2019

LOVELL, C. A. Knox; FRIED, Harold O.; SCHMIDT,Shelton. S. THE MEASUREMENT OF PRODUCTIVE EFFICIENCY AND PRODUCTIVITY GROWTH. New York: Oxford University Press, 2008. 638 p. Disponível em: 
VI CIDESPORT/2019

Congresso Internacional

de Desempenho Portuário

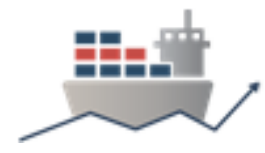

<http://pages.stern.nyu.edu/ wgreene/FrontierModeling/SurveyPapers/Lovell-Fried-

Schmidt.pdf>. Acesso em: 15 out. 2018.

LETA, Fabiana Rodrigues; MELLO, João Carlos C. B. Soares de; GOMES, Eliane Gon, calves. Métodos de Melhora de Ordenação em DEA Aplicados à Avaliação Estática de Tornos Mecânicos. Disponível em:

<http://www.scielo.mec.pt/pdf/iop/v25n2/v25n2a04.pdf>. Acesso em: 15 jun. 2019

LINES, Mitsui O.s.k. Annual Report 2017. Disponível em:

<https://www.mol.co.jp/en/ir/data/annual/pdf/ar-e2017.pdf>. Acesso em: 05 mar. 2019.

LOLLI, Paola Lemos. UTILIZAÇÃO DA ANÁLISE POR ENVOLTÓRIA DE DADOS (DEA) COMO MODELO PARA ANÁLISE DE EFICIÊNCIA FINANCEIRA. 2014.

Disponível em:

$<$ https://www.lume.ufrgs.br/bitstream/handle/10183/158376/001022066.pdf?sequenc $\mathrm{e}=1>$. Acesso em: 10 jun. 2019.

MAGALHÃES, Petrônio Sá Benevides. Transporte Marítimo - Cargas, Navios, Portos e Terminais. São Paulo: Aduaneiras, 2010.

MELLO, João Carlos Correia Baptista Soares de; MEZA, Lidia Angulo; GOMES, Eliane Gonçalves. CURSO DE ANÁLISE DE ENVOLTÓRIA DE DADOS. 2005.

Disponível em:

<https://www.researchgate.net/profile/Joao_Mello/publication/237473886_CURSO_D E_ANALISE_DE_ENVOLTORIA_DE_DADŌS/links/0deec5226afdc4f6790000000/CU RSO-DE-ANALISE-DE-ENVOLTORIA-DE-DADOS.pdf>. Acesso em: 15 maio 2019.

OLIVEIRA, Gabriel Figueiredo de; CARIOU, Pierre. A DEA study of the efficiency of 122 iron ore and coal ports and of $15 / 17$ countries in 2005. Maritime Policy \& Management: The Flagship Journal Of International Shipping And Port Research. Londres, p. 727-743. nov. 2011. Disponível em:

$<$ https://www.tandfonline.com/doi/pdf/10.1080/03088839.2011.625989?needAccess= true>. Acesso em: 22 abr. 2019.

PARÉ, Guy; TRUDEL, Marie-claude; JAANA, Mirou. Synthesizing information systems knowledge: A typology of literature reviews. Elsevier. Quebec, p. 183-199. jul. 2014. Disponível em:

<https://edisciplinas.usp.br/pluginfile.php/4126344/mod_resource/content/2/2.4.Pare \%20et\%20al.\%202015\%20-\%20literature\%20review.pdf>. Acesso em: 22 maio 2019.

PROFILLIDIS, V. A.; BOTZORIS, G. N. Evolution and Trends of Transport Demand. Disponível em:

<https://www.sciencedirect.com/topics/social-sciences/maritime-transport>. Acesso em: 10 maio 2019.

SOBRAL, Filipe; PECl, Alketa. Administração: teoria e prática no contexto brasileiro. 2. ed. São Paulo: Pearson, 2013.

THE Observatory of Economic Complexity. Disponível em: 
VI CIDESPORT/2019

Congresso Internacional

de Desempenho Portuário

<https://atlas.media.mit.edu/en/>. Acesso em: 30 maio 2019.

WILMSMEIER, Gordon; CULLINANE, Kevin P.b.; NOTTEBOOM, Theo. IAME 2012 Contemporary studies on maritime transport in Latin America. The Flagship Journal Of International Shipping And Port Research. Londres, p. 1-7. maio 2012. Disponivel em:

<https://www.tandfonline.com/doi/pdf/10.1080/03088839.2012.729700?needAccess= true>. Acesso em: 18 abr. 2019. 